\title{
SOLVENT EXTRACTION OF PALLADIUM(II) FROM ALKALINE CYANIDE SOLUTION BY THE DODECYL DIMETHYL-2-PHENOXYETHYL AMMONIUM BROMIDE
}

\author{
YAN. LIU, ZHANGJIE HUANG*, JINFEI LI, JING CHEN
}

School of Chemistry Science and Engineering, Yunnan University, Kunming 650091, China.

\begin{abstract}
The direct extraction of $\mathrm{Pd}(\mathrm{CN})_{4}{ }^{2-}$ from alkaline cyanide solutions with dodecyl dimethyl-2-phenoxyethyl ammonium bromide (DDPB) was investigated. Several factors affecting extraction efficiency, including DDPB concentration, modifier content, equilibrium time, phase ratio (O/A), $\mathrm{pH}$ and palladium concentration in aqueous phase, were studied. The results indicated that nearly all of the $\mathrm{Pd}(\mathrm{II})(>98 \%)$ was transferred from the aqueous phase into the organic phase. N-pentanol was the most appropriate modifier for the extraction of $\mathrm{Pd}(\mathrm{CN})_{4}{ }^{2-}$. Palladium can be separated efficiently by DDPB over base metals $(\mathrm{Fe}$ , $\mathrm{Co}, \mathrm{Ni}$ and $\mathrm{Cu}$ ) from alkaline cyanide medium. The extraction was quite fast and equilibrium could be established within 3 min. Most of Pd(II) ( $>96 \%)$ in the organic phase could be stripped with ammonium thiocyanate aqueous solutions, from which elemental palladium could potentially be recovered by the addition of hydrazine hydrate. The organic phase after stripping can be recycled for a continuous extraction-stripping operation. The extraction mechanism can be deduced based on FTIR spectrum and slope analysis while the mechanism of stripping can be explained by the principle of minimum charge density and Le Chatelier's principle. The proposed method was applied to extract palladium from real cyanide leaching liquor of Pd flotation concentrate with satisfactory results.
\end{abstract}

Keywords: Dodecyl dimethyl-2-phenoxyethyl ammonium bromide; Palladium; Alkaline cyanide solution; Solvent extraction.

\section{INTRODUCTION}

Extraction of palladium from ores is restricted to leaching in cyanide or chloride media. Subsequently, the leaching solutions are treated by zinc powder cementation or activated carbon adsorption for enrichment of palladium ${ }^{1,2}$ However, the content of palladium in zinc cementation concentrates is low, and it must be further refined by a long procedure. And the adsorption technique is very complicated and less selective in the presence of other coexisting impurity metal ions ${ }^{3}$. Fortunately, liquid/liquid solvent extraction not only can overcome these problems but also has a number of advantages, including simple technology, high production capacity, high selectivity and high product purity. As a result, studies on the direct solvent extraction of palladium from the leaching solutions have received much attention. Early studies on the solvent extraction of palladium mainly involved the extraction of palladium in aqueous acid solution. Chloride is the most common media into which all the precious metals, except silver, can be efficiently brought into solution. A number of studies on the extraction of palladium from hydrochloric acid solution have been carried out, and many different extraction systems have been examined, including oxime derivatives ${ }^{4,5}, 8$-hydroyquinoline derivatives ${ }^{6}$, neutral organophosphorus compound ${ }^{7}$, dialkyl, sulphoxide ${ }^{8-11}$ and phosphonium derivatives ${ }^{12}$ and so on.

In 1986, Mooiman ${ }^{13}$ reported that $\mathrm{Au}(\mathrm{CN})_{2}{ }^{-}$could be extracted directly from alkaline cyanide solution by modified amines. Following this report, a number of studies on the extraction of $\mathrm{Au}(\mathrm{CN})_{2}^{-}$from alkaline cyanide solution have been carried out, and many different extraction systems have been examined. Various extractants, such as amines derivatives ${ }^{14-15}$, guanidine derivatives ${ }^{16}$ and alkyl phosphorus esters ${ }^{17}$, etc., have been suggested to be suitable for gold(I) solvent extraction. In our group, we had studied a new extraction system to recover $\mathrm{Au}(\mathrm{I})$ directly from the alkaline cyanide solution. By adding quaternary ammonium salts cetyl trimethyl ammonium bromide (CTAB) with an equal molar ratio of $\mathrm{CTAB}$ versus $\mathrm{Au}(\mathrm{CN})_{2}$ - directly into the aurous aqueous phase in advance and them using tributyl phosphate (TBP) as extractant for extraction of $\mathrm{Au}(\mathrm{CN})_{2}^{-}$from alkaline cyanide solution ${ }^{18-20}$.

Unlike the extraction of $\mathrm{Au}(\mathrm{CN})_{2}^{-}$, the potential for recovery of palladium and other noble metals from their alkaline cyanide solutions by solvent extraction method is largely unexplored ${ }^{2}$. A literature survey of the above requirements revealed very little relevant information. In our group, we have studied the extraction of $\mathrm{Pd}(\mathrm{CN})_{4}^{2-}$ using Benzyl dimethyl-n-dodecylammonium chloride(BDMDC $)^{21}$. Almost all of the palladium in the aqueous phase was transferred into the organic phase when a certain amount of extractant was added. However, the procedure of palladium(II) extraction was in the single metal system, the possible interferences was not studied, which limited further research for industrial application. Up to now, no report has been found to extract palladium from real cyanide leaching liquor of Pd flotation concentrate. Here, we report our selectivity studies on novel Pd(II) extractants over Fe(III), $\mathrm{Co}(\mathrm{III}), \mathrm{Ni}(\mathrm{I})$ and $\mathrm{Cu}(\mathrm{I})$ from alkaline cyanide medium. Various parameters affecting the percentage extraction of palladium(II), such as the concentrations of long-chain alcohols, the concentrations of extractant, contact time, phase ratio $(\mathrm{O} / \mathrm{A})$, initial palladium concentration in aqueous phase, aqueous solution $\mathrm{pH}$ and stripping agent, were investigated. This study provides a novel route to extract palladium directly from alkaline cyanide solution. The proposed procedure was applied to extract palladium from real cyanide leaching liquor of Pd flotation concentrate.

\section{EXPERIMENTAL}

\section{Instruments and Reagents}

A Z-2000 polarized zeeman atomic absorption spectrophotometer (Hitachi High-Technologies Corporation, Japan) was used to measure the concentration of $\mathrm{Pd}(\mathrm{II})$. The operating conditions were carried out according to the recommendations of manufacturer. The wavelengths selected were as follows: Pd $247.6 \mathrm{~nm}$. A Fourier transform infrared spectrometer (FTIR, Thermo Nicolet 360-FTIR) was used for recording the FTIR spectra of all samples. The $\mathrm{pH}$ values were determined with a PHS-3C precision $\mathrm{pH}$ meter (REX Instrument Factory, Shanghai, China). Dodecyl dimethyl-2-phenoxyethyl ammonium bromide (DDPB), ammonium thiocyanate $\left(\mathrm{NH}_{4} \mathrm{SCN}\right)$, n-pentanol and benzene (analytical grade) were purchased from Beijing Chemical Reagent Co. $\operatorname{Pd}(\mathrm{CN})_{4}^{2-}$ and real cyanide leaching liquor were supplied by Yunnan Gold Group Co. Table 1 showed the typical chemical composition of cyanide leaching liquor from Pd flotation concentrate in Yunnan Da-Li region of China. Other chemicals were all commercially available reagents of analytical grade. $\mathrm{N}$-pentanol was chosen as a modifier. The organic phase was prepared by dissolving a weighed amount of DDPB in benzene with or without a modifier. The aqueous phase was prepared by diluting $\mathrm{Pd}(\mathrm{CN})_{4}{ }^{2-}$ in ultra-pure water.

\section{General extraction procedure}

Equal volumes $(80 \mathrm{~mL})$ of both phases were mixed and vigorously shaken for $3 \mathrm{~min}$, which was sufficient enough to attain equilibrium in a preliminary experiment. After phase separation, the concentration of metal ion in aqueous solution was determined by an atomic absorption photometer and concentration of metal ion in the organic phase was calculated by mass balance. These results were further used to estimate the extraction efficiency of metal. Typically, the volume percentage of n-pentanol in the organic phase was $30 \%(\mathrm{v} / \mathrm{v})$. The $\mathrm{pH}$ of the aqueous solution was adjusted to about 10.5 . Pd(II) was extracted by $0.01 \mathrm{M} \mathrm{DDPB}+30 \%(\mathrm{v} / \mathrm{v}) \mathrm{n}$-pentanol in benzene. The experiment was carried out at room temperature $\left(25 \pm 1^{\circ} \mathrm{C}\right)$.

\section{RESULTS AND DISCUSSION}

\section{Effect of modifiers content on the extraction}

Several long-chain alcohols were tested for their usage as modifiers for the extraction of $\mathrm{Pd}(\mathrm{CN})_{4}^{2-}$. The parameters of experiments were fixed: initial $\mathrm{Pd}(\mathrm{II})$ concentration in the aqueous phase, $100 \mathrm{mg} \cdot \mathrm{L}^{-1}$; DDPB concentration in the organic phase, $0.01 \mathrm{M}$; initial $\mathrm{pH}$ in aqueous solution, 10.5; organic/aqueous 
$(\mathrm{O} / \mathrm{A})$ phase ratio, 1.0; and mixing time, $3 \mathrm{~min}$. The results are summarized in Fig.1. It illustrates that long-chain alcohols have an obvious effect on the extraction process. Without long-chain alcohols, the percentage extraction of palladium is lower than $50 \%$. The extraction efficiency increases significantly when long-chain alcohols content in the organic phase is increased from 10 to $30 \%(\mathrm{v} / \mathrm{v})$. When their content in the organic is $30 \%(\mathrm{v} / \mathrm{v})$, the extraction percentage of palladium is higher than $75 \%$. Further increasing long-chain alcohols content from 30 to $50 \%(\mathrm{v} / \mathrm{v})$, the percentage extraction of palladium remains slightly increases. N-pentanol is the most appropriate modifier for the extraction of Pd(II). When the volume percentage of n-pentanol in the organic is $30 \%(\mathrm{~V} / \mathrm{V})$, the percentage extraction of $\mathrm{Pd}(\mathrm{II})$ is higher than $98 \%$. The addition of long-chain alcohols remarkably enhances the extraction efficiency of the extraction system. Furthermore, it has been observed that the separation of organic and aqueous phases was very difficult and more than 24 hours were needed for the complete separation of two phases. By comparison, the addition of $30 \%(\mathrm{v} / \mathrm{v}) \mathrm{n}$-pentanol facilitates the separation of two phases, leading to the separation time of two phases less than 3 minutes.

Table 1. Chemical composition of the cyanide leaching liquor from Pd flotation concentrate in Yunnan Da-Li (YD, PRC)

\begin{tabular}{|c|c|c|c|c|c|}
\hline Metals & $\mathrm{Pd}(\mathrm{CN})_{4}{ }^{2-}$ & $\mathrm{Fe}(\mathrm{CN})_{6}{ }^{3-}$ & $\mathrm{Co}(\mathrm{CN})_{6}{ }^{3-}$ & $\mathrm{Ni}_{2}(\mathrm{CN})_{6}{ }^{4-}$ & $\mathrm{Cu}(\mathrm{CN})_{4}{ }^{3-}$ \\
\hline Mining leaching liquor $(\mathrm{mg} / \mathrm{L})$ & 85.2 & 14.3 & 6.7 & 3.4 & 7.6 \\
\hline
\end{tabular}

The addition of n-pentanol into the organic phase not only contributed to the increase of the extraction percentage of palladium, but also shortened tremendously the separation time of two phases. This means that n-pentanol was used as phase modifiers to prevent emulsions or third phases forming during the extraction.

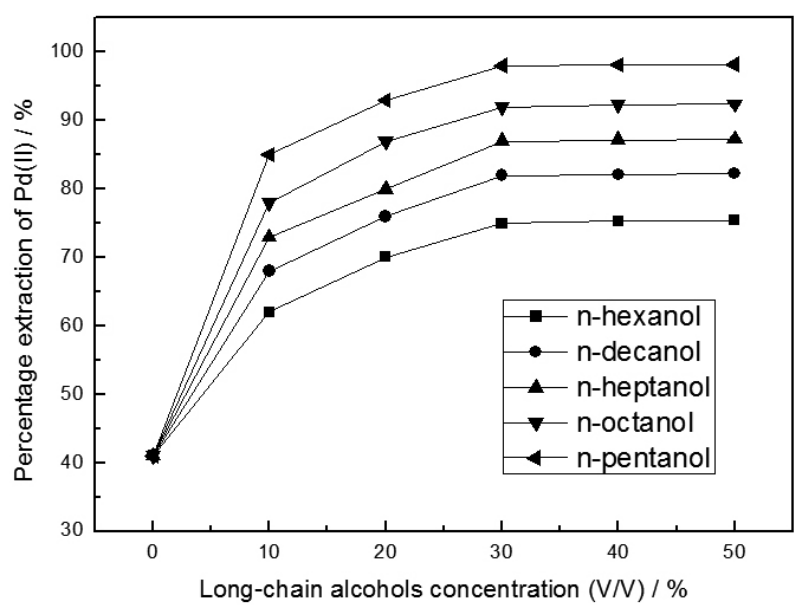

Fig. 1. Effect of different long-chain alcohols on the extraction percentage

\section{Effect of extractant concentration on the extraction}

To study the effect of DDPB concentration on the Pd(II) extraction efficiency, experiments were performed on conditions of initial $\mathrm{Pd}(\mathrm{II})$ concentration, $100 \mathrm{mg} \cdot \mathrm{L}^{-1}$; phase ratio $(\mathrm{O} / \mathrm{A}), 1.0 ; \mathrm{pH}$ in aqueous solution, 10.5 ; the volume percentage of n-pentanol in the organic, $30 \%(\mathrm{~V} / \mathrm{V})$; and equilibrium time $3 \mathrm{~min}$. The experimental results are shown in Fig.2. It illustrates that DDPB concentration has an obvious effect on the extraction process. The extraction efficiency increases significantly when DDPB concentration is increased from 0.002 to $0.01 \mathrm{M}$. The extraction efficiency is $98.3 \%$ when DDPB concentration is $0.01 \mathrm{M}$. However, further increase of the DDPB concentration from 0.01 to $0.02 \mathrm{M}$ does not result in a clear increase of the extraction efficiency.

In addition, the percentage extraction of Pd(II) is zero, when no DDPB is added in the organic phase, indicating that n-pentanol cannot extract $\mathrm{Pd}(\mathrm{CN})_{4}^{2-}$ by itself, but it can positively improve Pd(II) extraction with DDPB.

\section{Effect of contact time on the extraction}

To investigate the effect of contact time of organic and aqueous phases on $\mathrm{Pd}(\mathrm{II})$ extraction, the parameters of experiments were fixed: initial $\mathrm{Pd}(\mathrm{II})$ concentration, $100 \mathrm{mg} \cdot \mathrm{L}^{-1}$; phase ratio $(\mathrm{O} / \mathrm{A}), 1.0$; initial $\mathrm{pH}$ in aqueous solution, 10.5; the volume percentage of n-pentanol in the organic, $30 \%(\mathrm{~V} / \mathrm{V})$; and DDPB concentration in the organic phase was $0.01 \mathrm{M}$. The results are plotted in Fig.3, which shows that contact time of organic and aqueous phases has a remarkable effect on $\mathrm{Pd}(\mathrm{II})$ extraction. The two phases were shaken for a period ranging from 1 to $6 \mathrm{~min}$. As time increases from 1 to $3 \mathrm{~min}$, the percentage extraction of $\mathrm{Pd}(\mathrm{II})$ raises from 82 to $98.3 \%$. Further increasing contact time from $3 \mathrm{~min}$ to $6 \mathrm{~min}$, the percentage extraction of Pd(II) remains almost constant. Extraction equilibrium can be established within $3 \mathrm{~min}$. Therefore, the minimum period of equilibration required for the quantitative extraction of $\mathrm{Pd}(\mathrm{II})$ was found to be about $3 \mathrm{~min}$. Furthermore, the equilibrium time is shorter at higher concentration of n-pentanol in the organic phase. The experiments further verify that the addition of $n$-pentanol in the organic phase can shorten the phase separation time.

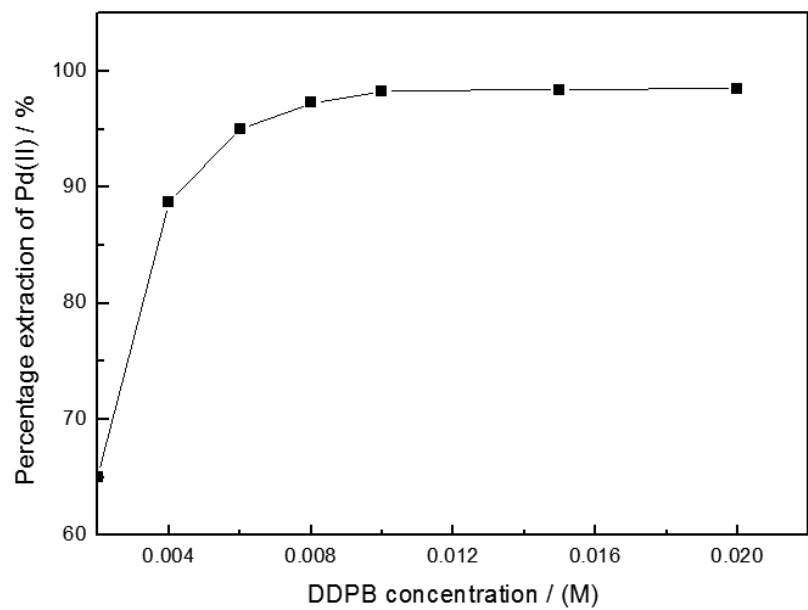

Fig. 2. Effect of extractant concentration on the extraction of Pd(II)

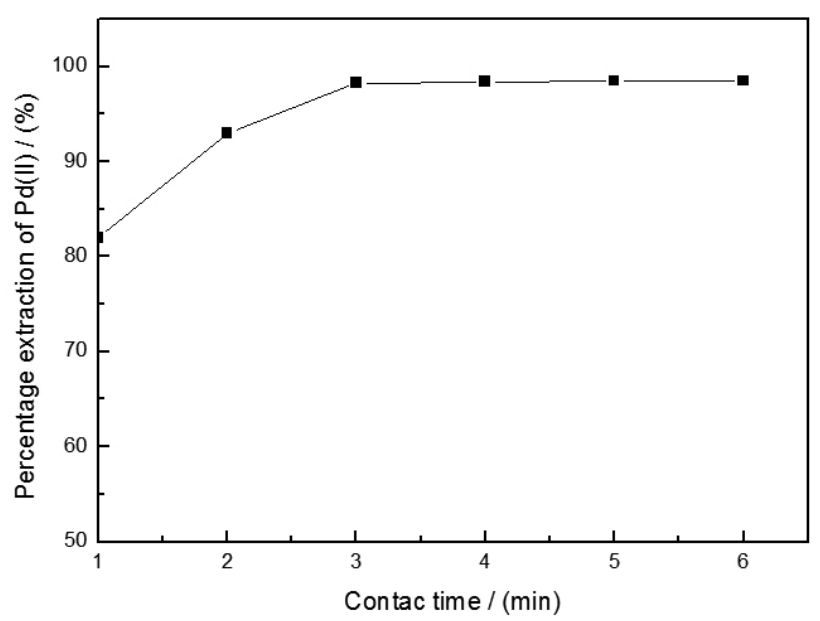

Fig. 3. Effect of contact time on extraction of Pd(II)

\section{Effect of phase ratio $(\mathrm{O} / \mathrm{A})$ on the extraction}

In order to investigate the effect of phase ratio $(\mathrm{O} / \mathrm{A})$ on $\mathrm{Pd}(\mathrm{II})$ extraction, a series of the following experiments were performed. Conditions of the extraction process were as follows: initial Pd(II) concentration, $100 \mathrm{mg} \cdot \mathrm{L}^{-1}$; initial $\mathrm{pH}$ in aqueous solution, 10.5; DDPB concentration in the organic phase, $0.01 \mathrm{M}$; the volume percentage of n-pentanol in the organic, $30 \%(\mathrm{~V} / \mathrm{V})$; and mixing time, $3 \mathrm{~min}$. The results are plotted in Fig.4. As can be seen from Fig.4, by increasing phase ratio $(\mathrm{O} / \mathrm{A})$ from 0.25 to 1.0 , the percentage extraction of 
Pd(II) increasing from 45.1 to $98.3 \%$. When phase ratio (O/A ) is over 1.0 , the percentage extraction of $\mathrm{Pd}(\mathrm{II})$ will remain constant. Therefore, $\mathrm{Pd}(\mathrm{II})$ can be extracted efficiently by controlling organic/ aqueous (O/A ) phase ratio, 1.0.

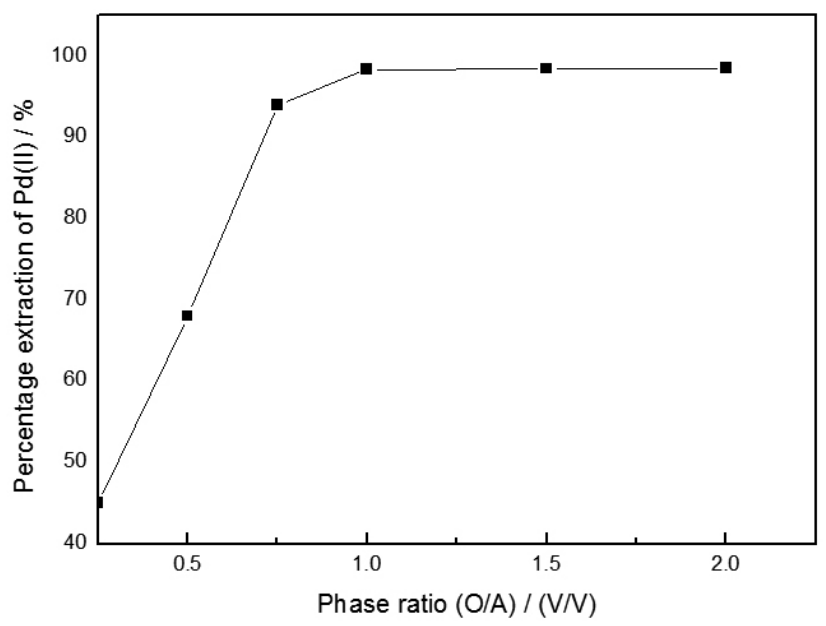

Fig. 4. Effect of phase ratio (O/A) on extraction of $\mathrm{Pd}(\mathrm{II})$

Effect of palladium concentration in the aqueous phase on the extraction

The palladium concentration of cyanide leaching solution in industry was very low, only about $20 \mathrm{mg} \cdot \mathrm{L}^{-1}$ to $200 \mathrm{mg} \cdot \mathrm{L}^{-1}$ The palladium concentration depends on the ore grade and the leaching process parameters. The influence of the variation of the initial $\mathrm{Pd}$ (II) concentration in the aqueous phase on the extraction has been studied. These tests were carried out with an initial $\mathrm{pH}$ in aqueous solution, 10.5; DDPB concentration in the organic phase, $0.01 \mathrm{M}$; the volume percentage of n-pentanol in the organic, $30 \%(\mathrm{~V} / \mathrm{V})$; and mixing time, 3 min. The results are presented in Fig.5. As can be seen in Fig. 5, with increasing initial palladium(II) concentration from 20 to $100 \mathrm{mg} \cdot \mathrm{L}^{-1}$, the percentage extraction of palladium merely has a slight decreases(from 99.5 to $98.3 \%$ ). Further increasing initial palladium(II) concentration from 100 to 250 $\mathrm{mg} \cdot \mathrm{L}^{-1}$, the percentage extraction of palladium decreases rapidly (from 98.3 to $78.1 \%)$.

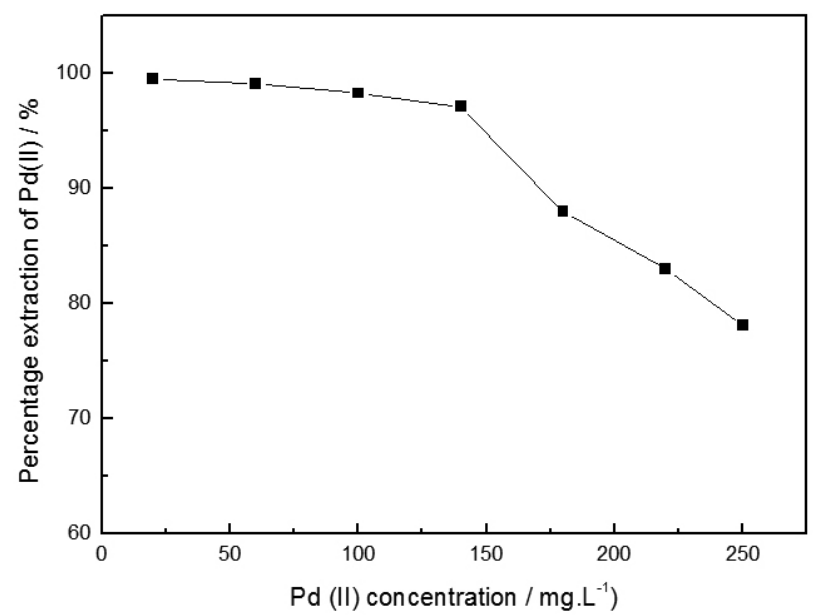

Fig. 5. Effect of initial palladium concentration on extraction of Pd(II)

\section{Effect of aqueous solution $\mathrm{pH}$ on the extraction}

The extraction of palladium from cyanide solutions at different $\mathrm{pH}$ value was also investigated. Experiments were conducted to investigate the effect of aqueous solution $\mathrm{pH}$ on palladium extraction for initial palladium concentration, $100 \mathrm{mg} \cdot \mathrm{L}^{-1}$; DDPB concentration, $0.01 \mathrm{M}$; the volume percentage of n-pentanol in the organic, $30 \%(\mathrm{~V} / \mathrm{V})$; phase ratio $(\mathrm{O} / \mathrm{A}), 1.0$; and equilibrium time 3 minutes. The results percentage extraction of $\mathrm{Pd}(\mathrm{II})$ versus equilibrium $\mathrm{pH}$ are shown in Fig.6. As shown in fig. 6, the percentage extraction of palladium does not change much when the $\mathrm{pH}$ value is below 11.0. Under such conditions almost all of the palladium $(>98 \%)$ was transferred into the organic phases. With the $\mathrm{pH}$ of aqueous phase further increases, the percentage extraction of palladium decreases dramatically. Given that the $\mathrm{pH}$ value of the palladium cyanide leaching solution in industry is usually in the range of 9 to $11^{22}$, the initial $\mathrm{pH}$ of the aqueous phase was selected in this study to be 10.5 .

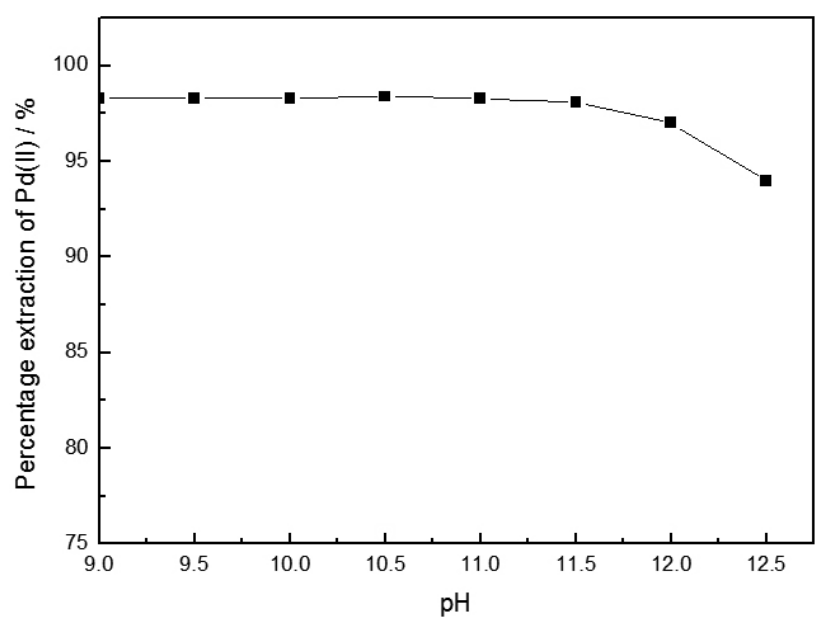

Fig. 6. Effect of $\mathrm{pH}$ on the extraction of $\mathrm{Pd}(\mathrm{II})$

Palladium stripping from loaded organic phases by $\mathrm{NH}_{4} \mathrm{SCN}$

In the present work, $\mathrm{NH}_{4} \mathrm{SCN}$ solution was employed as the stripping reagent of palladium loaded organic phase. The stock palladium-loaded organic phase was prepared by the same extraction procedure as described above.

The following parameters were fixed: palladium concentration in loaded organic phase, $98 \mathrm{mg} \cdot \mathrm{L}^{-1}$; organic / aqueous $(\mathrm{O} / \mathrm{A})$ phase ratio, 4.0 ; and mixing time of two phases, 5 min. Fig. 7 showed the effect of $\mathrm{NH}_{4} \mathrm{SCN}$ concentration in the aqueous phase on the stripping of $\mathrm{Pd}(\mathrm{II})$. As shown in Fig.7, with the increase of $\mathrm{NH}_{4} \mathrm{SCN}$ concentration, the percentage stripping of $\mathrm{Pd}(\mathrm{II})$ increased significantly before the $\mathrm{NH}_{4} \mathrm{SCN}$ concentration was lower than $0.2 \mathrm{M}$. Further increasing $\mathrm{NH}_{4} \mathrm{SCN}$ concentration, the percentage stripping of $\mathrm{Pd}(\mathrm{II})$ has changed little. At this stage, most of $\mathrm{Pd}(\mathrm{II})(>96 \%)$ was transferred into the aqueous phase. This means that $\mathrm{NH}_{4} \mathrm{SCN}$ is an excellent stripping agents from a loaded organic phase of DDPB-n-pentanol system.

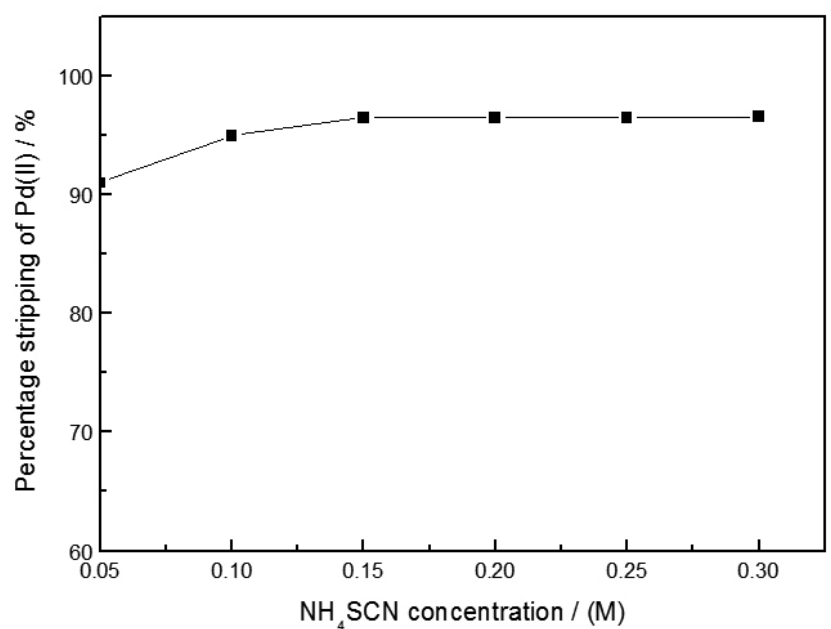

Fig. 7. Effect of stripping reagent concentration on the stripping of $\mathrm{Pd}(\mathrm{II})$

The reduction of $\mathrm{Pd}(\mathrm{CN})_{4}{ }^{2-}$ after stripping

Palladium(II) in the $\mathrm{NH}_{4}{ }_{4}^{4} \mathrm{SCN}$ strip product solution should be finally isolated as palladium metal. Hydrazine hydrate was employed to reduce palladium(II) from the $\mathrm{NH}_{4} \mathrm{SCN}$ stripping solutions. It was found that a dark precipitate formed in the aqueous phase upon adding a certain amount of hydrazine hydrate solution. The results are plotted in Fig.8. As can be seen from 
Fig.8, the reduction percentage increases as hydrazine hydrate concentration increases. When the concentration of hydrazine hydrate reaches $0.5 \%(\mathrm{w} / \mathrm{w})$, the percentage reduction of Pd(II) approaches $99 \%$. Ammonium oxalate and sodium sulfite was found also to be capable of reducing Pd(II) to Pd metal, but the reduce rate was much slower than that of hydrazine hydrate. Hydrazine hydrate is obviously an efficient reducing agent. The obtained palladium metal powder can be isolated by filtration.

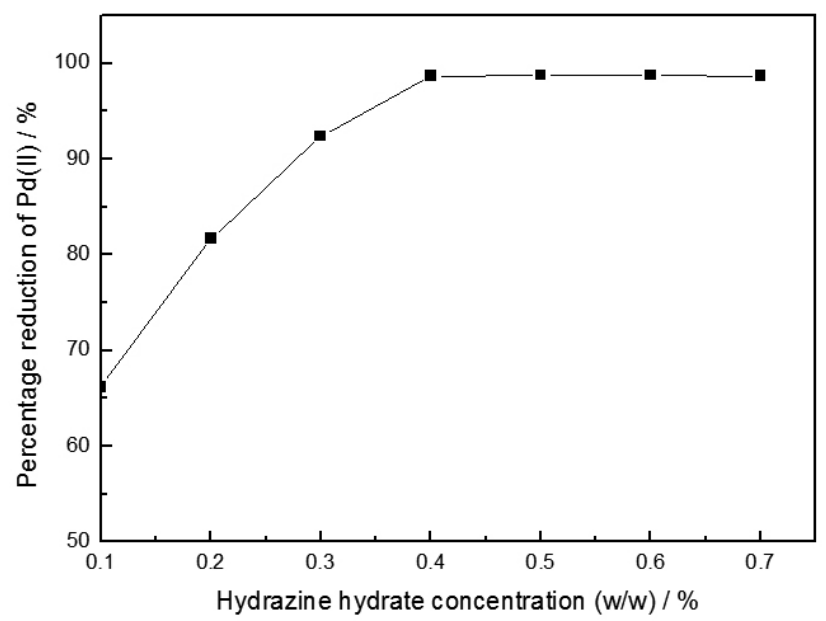

Fig. 8. Effect of hydrazine hydrate concentration on the reduction of $\mathrm{Pd}(\mathrm{II})$

The reuse behavior of the organic phase after stripping

It is important that the organic phase can be reused after the stripping process for economical and environmental reasons. In the present work, the reuse of the organic phases after palladium stripping was investigated. For continuous operation, the organic phase should be reproduced after a stripping process. The organic phase after palladium stripping was contacted with $2.0 \mathrm{M}$ $\mathrm{KBr}$ solutions for regeneration. To investigate the reuse of DDPB-n-pentanol system, the regenerated organic phase was used to extract another alkaline cyanide solution with $100 \mathrm{mg} \cdot \mathrm{L}^{-1} \mathrm{Pd}(\mathrm{II})$. The results show that most of $\mathrm{Pd}(\mathrm{II})$ $(>98 \%$ ) could be extracted into the recycled organic phase and the recovery ratio of $\mathrm{Pd}(\mathrm{II})$ was more than $95.5 \%$. With further cycles (totally 6 cycles), the extraction percentage without significant loss and the recovery ratio of $\mathrm{Pd}(\mathrm{II})$ was always more than $95.0 \%$ in the processes. Figure 9 presented the obtained results. It is concluded that the reuse of the organic phase for industrial application is possible.

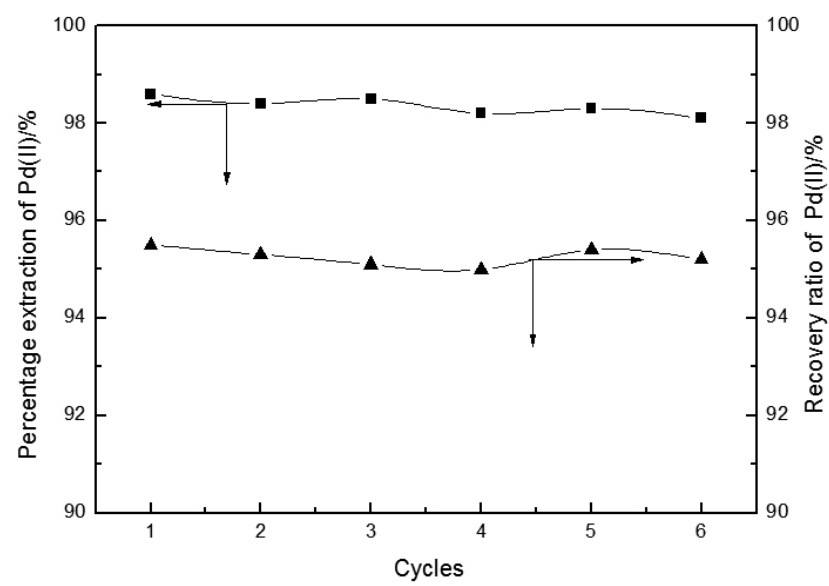

Fig. 9. The extraction behavior of the regenerated organic phase

Experiments with Real Cyanide Leaching Liquor from Pd flotation concentrate

Experiments with a real cyanide leaching solution of Pd flotation concentrate in Yunnan Da-Li region of China were also carried out, and the results were shown in Table 2. From the results obtained in Table 2, the yield of of Pd(II) extraction amounts to $99.1 \%$, whereas that of $\mathrm{Fe}(\mathrm{III}), \mathrm{Co}(\mathrm{III}), \mathrm{Ni}(\mathrm{I})$ or $\mathrm{Cu}(\mathrm{I})$ is lower than 4\%. By calculation, the separation factors of Pd(II) and other metal ions are over $2.0 \times 10^{3}$, indicating that the selectivity of palladium extraction in the presence of other metals is higher ${ }^{12}$. Palladium can be separated efficiently by DDPB over base metals ( $\mathrm{Fe}, \mathrm{Co}, \mathrm{Ni}$ and $\mathrm{Cu}$ ) from alkaline cyanide medium. According to the principle of minimum charge density, a large size anion with small surface charge density was easier to be extracted into the organic phase $^{20}$. The extractive selectivity for different metal ions followed the order of $\mathrm{Pd}(\mathrm{CN})_{4}{ }^{2-}>\mathrm{Fe}(\mathrm{CN})_{6}^{3-} \approx \mathrm{Co}(\mathrm{CN})_{6}^{3-}>\mathrm{Ni}_{2}(\mathrm{CN})_{6}^{4-}>\mathrm{Cu}(\mathrm{CN})_{4}^{3-}$.

The palladium stripping efficiency of $97.2 \%$ could be reached with $\mathrm{NH}_{4} \mathrm{SCN}$ concentration, $0.2 \mathrm{M}$; phase ratio(O/A), 4.0; and retention time of 5 minutes.

Experiments with real cyanide leaching liquor indicated that there was no more difference of extraction of $\mathrm{Pd}(\mathrm{II})$ between, with, or without other meta ions in the alkaline cyanide solution. Almost all of Pd(II) could be transferred into the organic phase, $\mathrm{Fe}(\mathrm{III}), \mathrm{Co}(\mathrm{III}), \mathrm{Ni}(\mathrm{I})$ and $\mathrm{Cu}(\mathrm{I})$ were poorly extracted by DDPB, which demonstrated that other metal ions had hardly any influence on the Pd(II) extraction. It is concluded that extraction of palladium with DDPB from alkaline cyanide solutions is efficient and highly selective, the DDPB system can be applied to extract palladium from real cyanide leaching liquor of Pd flotation concentrate.

Table2. Extraction Pd(II) from leaching solution of Pd flotation concentrate

\begin{tabular}{|c|c|c|c|c|c|}
\hline Metals & $\begin{array}{c}\mathrm{Pd} \\
(\mathrm{CN})_{4}^{2-}\end{array}$ & $\begin{array}{c}\mathrm{Fe} \\
(\mathrm{CN})_{6}^{3-}\end{array}$ & $\begin{array}{c}\mathrm{Co} \\
(\mathrm{CN})_{6}^{3-}\end{array}$ & $\begin{array}{c}\mathrm{Ni}_{2} \\
(\mathrm{CN})_{6}{ }^{4-}\end{array}$ & $\begin{array}{c}\mathrm{Cu} \\
(\mathrm{CN})_{4}^{3-}\end{array}$ \\
\hline $\begin{array}{c}\text { Extraction } \\
\text { percentage(\%) }\end{array}$ & 99.1 & 3.9 & 3.8 & 1.8 & 1.2 \\
\hline $\begin{array}{c}\text { Separation } \\
\text { factor }\left(\beta_{\mathrm{Pd} / \mathrm{M}}\right)\end{array}$ & & $2.7 \times 10^{3}$ & $2.8 \times 10^{3}$ & $6.0 \times 10^{3}$ & $9.1 \times 10^{3}$ \\
\hline
\end{tabular}

Slope analysis

Pd(II) was extracted in systems containing 0.002 to $0.020 \mathrm{M}$ DDPB with $30 \%(\mathrm{v} / \mathrm{v}) \mathrm{n}$-pentanol in the organic phase. At up to $0.010 \mathrm{M}$ DDPB in the organic phase, a linear increase in the extraction of $\mathrm{Pd}(\mathrm{II})$ was observed. At $0.010 \mathrm{M}$ DDPB in the organic phase, $98.3 \%$ of Pd(II) was extracted. The ratio of metal ion to DDPB in the extracted species was determined by plotting $\log \mathrm{D}$ (D: distribution ratio) versus $\log [\mathrm{DDPB}]$ at fixed $\mathrm{pH}$.

The mechanism for Pd(II) extraction from cyanide medium using DDPB was deduced to be:

$$
\mathrm{Pd}(\mathrm{CN})_{4}^{2-} \text { (aq) }^{2}+\mathrm{nDDP}^{+} \text {(org) } \leftrightarrow\left[\left(\mathrm{DDP}^{+}\right)_{\mathrm{n}} \mathrm{Pd}(\mathrm{CN})_{4}^{2-}\right]_{(\text {org })}
$$

The subscripts aq and org denote the species in the aqueous and organic phases, respectively. The equilibrium constant can be written:

$$
\mathrm{K}_{\mathrm{S}}=\frac{\left[\left(\mathrm{DDP}^{+}\right)_{\mathrm{n}} \mathrm{Pd}(\mathrm{CN})_{4}^{2-}\right]_{(\mathrm{org})}}{\left[\operatorname{Pd}(\mathrm{CN})_{4}^{2-}(\mathrm{aq})\left[\mathrm{DDP}^{+}{ }_{(\mathrm{org})}\right]^{\mathrm{n}}\right.}
$$

Taking the log of both sides and rearranging:

$$
\log \mathrm{D}=\log _{\mathrm{S}}+\mathrm{n} \log \left[\mathrm{DDP}{ }^{+}{ }_{(\mathrm{org})}\right]
$$

Where $\mathrm{D}$ is the distribution ratio for palladium(II). The palladium(II) distribution ratio (D) between the organic and aqueous phase was calculated as the ratio of total palladium (II) concentration in both phases:

$$
\mathrm{D}=\frac{\left[\mathrm{Pd}(\mathrm{CN})_{4}^{2-}\right]_{(\mathrm{org})}}{\left[\mathrm{Pd}(\mathrm{CN})_{4}^{2-}\right]_{(\mathrm{aq})}}
$$

Hence, a $\log \mathrm{D}$ versus $\log \left[\mathrm{DDP}^{+}{ }^{+}{ }_{(0 r g}\right]$ plot, will have a slope equal to $\mathrm{n}$.

As can be seen in Fig.10, when DDPB concentration is less than 0.011 $\mathrm{M}, \log \mathrm{D}$ is a linear function against $\log [\mathrm{DDPB}]$ with a slope of 2.13 . From the results of Fig.10 and Eq.(3), the constant $\mathrm{n}$ is proposed to be 2, which means there might be two DDPB molecules were involved in the formation of the extracted species. The composition of the extracted species could be 1:2 for $\mathrm{Pd}(\mathrm{CN})_{4}{ }^{2-}$ and DDPB. So the extraction of Pd(II) by DDPB may be depicted as:

$\operatorname{Pd}(\mathrm{CN})_{4}^{2-}{ }_{\text {(aq) }}+2 \mathrm{DDP}^{+}{ }_{\text {(org) }} \leftrightarrow\left[\left(\mathrm{DDP}^{+}\right)_{2} \mathrm{Pd}(\mathrm{CN})_{4}^{2-}\right]_{(\text {org })}$ 


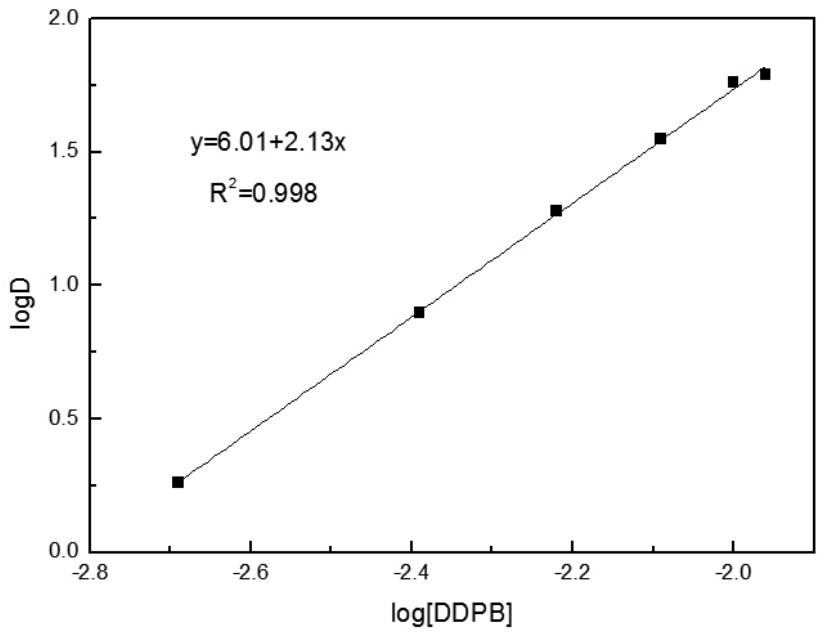

Fig. 10. Plot of $\log D$ versus $\log [\mathrm{DDPB}]$

\section{Infrared spectrum analysis}

Extracted species of Pd(II)-DDPB may be prepared by following procedure: $0.1 \mathrm{M}$ DDPB in benzene and n-pentanol was shaken with 2.0 $\mathrm{g} \cdot \mathrm{L}^{-1} \mathrm{Pd}(\mathrm{CN})_{4}^{2-}$ aqueous solution (initial $\mathrm{pH}$ in aqueous solution, 10.5) until a saturated extraction organic phase was obtained. After removing benzene and n-pentanol by distillation, the extracted species was obtained. The FTIR spectrum images of DDPB and that of the extracted species are shown in Fig.11. The broad absorption peak at $3380 \mathrm{~cm}^{-1}$ is associated with the asymmetric and symmetric stretching vibrations of the $-\mathrm{OH}$ group of absorbed water molecules. The strongest absorption peaks in 2925 and $2850 \mathrm{~cm}^{-1}$ attributed to stretching vibrations of the $\mathrm{C}-\mathrm{H}$ bond of $-\mathrm{CH}_{3}$ and $-\mathrm{CH}_{2}$ group of DDPB. The weak peaks from 1500 to $1640 \mathrm{~cm}^{-1}$ originated from the $\mathrm{C}=\mathrm{C}$ and C-C bond. The C-N skeletal stretching vibrations observed at $1057 \mathrm{~cm}^{-1}$ for DDPB. In extracted species of Pd(II)-DDPB, the characteristic absorption of C-N stretching vibration appears at $1056 \mathrm{~cm}^{-1}$ and it does not shift remarkably. This suggested that DDPB is not coordinated with palladium(II) through the $\mathrm{N}$ atom. FTIR spectroscopy reveals that DDPB coordination environment was the same before and after extraction, no specific interaction such as coordination occurs between the palladium ions and DDPB extractant. On the basis of FTIR spectrum and slope analysis, the mechanism of extraction $\operatorname{Pd}(\mathrm{CN})_{4}{ }^{2-}$ from alkaline cyanide solution with DDPB follows an ion-association mechanism.

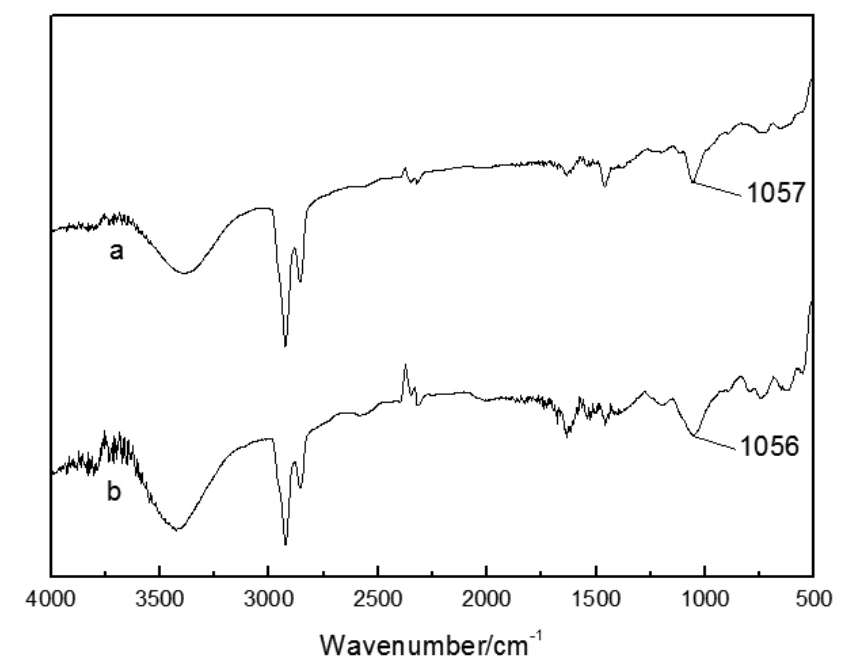

Fig. 11. Infrared spectrum of DDPB(a) and the extracted species(b)

The possible mechanism of stripping

$\mathrm{NH}_{4} \mathrm{SCN}$ exists as $\mathrm{NH}_{4}^{+}$and $\mathrm{SCN}^{-}$in the aqueous phase. It is well known that the large cation such as $\mathrm{DDP}^{+}$tends to combine with a large anion to form an easily extractable ion-pair. $\mathrm{SCN}^{-}$is such a bulky anion. When $\mathrm{NH}_{4} \mathrm{SCN}$ aqueous solution was mixed with the palladium-loaded organic phase, competition occurred between $\mathrm{SCN}^{-}$and $\mathrm{Pd}(\mathrm{CN})_{4}{ }^{2-}$ for combination with $\mathrm{DDP}^{+}$ to form an ion-pair. Firstly, The stripping of the palladium by $\mathrm{NH}_{4} \mathrm{SCN}$ is based on the principle of minimum charge density ${ }^{23}$. Because the surface charge density of the $\mathrm{SCN}^{-}$is lower than that of $\mathrm{Pd}(\mathrm{CN})_{4}{ }^{2-}$, the interaction of $\mathrm{SCN}^{-}$with $\mathrm{DDP}^{+}$was stronger than that of $\mathrm{Pd}(\mathrm{CN})_{4}{ }_{4}^{2-}$ with $\mathrm{DDP}^{+}$. Secondly, Le Chatelier's principle ${ }^{24}$ readily accounts for the fact that stripping of the palladium is benefited by the increased concentration of $\mathrm{SCN}^{-}$The concentration of $\mathrm{SCN}^{-}$ $(0.2 \mathrm{M})$ in the aqueous phase was much higher than that of $\operatorname{Pd}(\mathrm{CN})_{4}{ }_{4}^{2-}(0.001$ $\mathrm{M})$ in the organic phase, so when $\mathrm{NH}_{4} \mathrm{SCN}$ aqueous solution contacted with the palladium loaded organic phase, most $\mathrm{Pd}(\mathrm{CN})_{4}{ }_{4}{ }^{2-}$ could be replaced by the $\mathrm{SCN}^{-}$. The stripping reaction for the $\mathrm{NH}_{4} \mathrm{SCN}$ system might be as follows:

$$
\begin{aligned}
& {\left[\left(\mathrm{DDP}^{+}\right)_{2}\right]\left[\mathrm{Pd}(\mathrm{CN})_{4}^{2-}\right]_{(\mathrm{org})}+2 \mathrm{SCN}_{(\mathrm{aq})}^{-}} \\
& \rightarrow 2\left[\mathrm{DDP}^{+}\right]\left[\mathrm{SCN}^{-}\right]_{(\mathrm{org})}+\operatorname{Pd}(\mathrm{CN})_{4}^{2-}(\mathrm{aq})
\end{aligned}
$$

(where aq and org represent the aqueous and organic phases, respectively).

From this equation, one can deduce that the mechanism of stripping palladium from palladium-loaded organic phase follows an ion-exchange mechanism.

\section{CONCLUSIONS}

The direct extraction of palladium (II) from alkaline cyanide solution by DDPB was investigated. The percentage extraction of Pd(II) increases with increasing DDPB concentration, but decreases with the increase of initial palladium concentration. $\mathrm{N}$-pentanol is the most appropriate modifier for the extraction of $\mathrm{Pd}(\mathrm{II})$. The extraction was quite fast and equilibrium could be established within $3 \mathrm{~min}$. The results indicated that nearly all of the $\mathrm{Pd}(\mathrm{II})$ ( $>98 \%$ ) was transferred from the aqueous phase into the organic phase. Over $96 \%$ of palladium(II) can be stripped effectively with $0.2 \mathrm{M}$ of $\mathrm{NH}_{4} \mathrm{SCN}$ solution. The organic phase after stripping can be recycled for a continuous extraction-stripping operation. The Pd(II) can easily be reduced and isolated by addition of hydrazine hydrate solution after it is stripped by $\mathrm{NH}_{4} \mathrm{SCN}$.

The relationship between the $\log \mathrm{D}$ against $\log [\mathrm{DDPB}]$ plot indicate that the stoichiometry of the extracted species is a 2:1 complex, namely, $\left(\mathrm{DDP}^{+}\right)_{2} \cdot\left[\mathrm{Pd}(\mathrm{CN})_{4}{ }^{2-}\right]$. FTIR spectroscopy reveals that DDPB coordination environment was the same before and after extraction, no specific interaction such as coordination occurs between the palladium ions and DDPB extractant. The mechanism of extraction Pd(II) from alkaline cyanide solution with DDPB follows an ion-association mechanism. On the basis of the principle of minimum charge density and Le Chatelier's principle, the mechanism of stripping palladium from palladium-loaded organic phase follows an ionexchange mechanism. The proposed method was applied to extract palladium from real cyanide leaching liquor of Pd flotation concentrate in Yunnan Da-Li region of China. Palladium can be separated efficiently by DDPB over base metals $(\mathrm{Fe}, \mathrm{Co}, \mathrm{Ni}$ and $\mathrm{Cu}$ ) from alkaline cyanide medium. Our suggested extraction and stripping agents and recommended experimental conditions in this paper may provide a basis for industrial recovery of palladium from an alkaline cyanide solution.

\section{ACKNOWLEDGEMENT}

This work was financially supported by the National Natural Science Foundation of China (No.51264038), Science and Technology Support Program of China (2008BAB32B10) and Major State Basic Research Development Program of China (973 Program, No. 2014CB643406).

\section{REFERENCES}

1.- J. Y. Lee, B. Raju, B. N. Kumar, J. R. Kumar, H. K. Park and B. R. Reddy, Sep. Purif. Technol., 73, 213 (2010).

2.- C. N. Mpinga, S. M. Bradshaw, G. Akdogan, C. A. Snyders and J. J. Eksteen, Miner. Eng., 55,11 (2014).

3.- C. N. Mpinga, S. M. Bradshaw, G. Akdogan, C. A. Snyders and J. J. Eksteen, Hydrometallurgy, 142, 36 (2014).

4.- Y. F. Shen and W. Y. Xue, Sep. Purif. Technol., 56, 278 (2007).

5.- A. Cieszynska and M. Wisniewski, Sep. Purif. Technol., 73, 202 (2010).

6.- B. Cote and G. P. Demopoulos, Solvent Extr. Ion Exch., 12, 393 (1994).

7.- V. I. Men'shikov, I. Yu. Voronova, O. A. Proidakova, S. F. Malysheva, N. I. Ivanova, N. A. Belogorlova, N. K. Gusarova and B. A. Trofimov, Russ. 
J. Appl. Chem., 82, 183 (2009).

8.- L. Pan, X. Bao and G. Gu, J. Min. Metall. Sect. B-Metall., 49, 57 (2013).

9.- L. Pan and Z. D. Zhang, Miner. Eng., 22, 1271 (2009).

10.- Y. W. Li, G. B. Gu, H. Y. Liu, H. H. Y. Sung, I. D. Williams and C. K. Chang, Molecules, 10, 912 (2005).

11.- J. S. Preston and A. C. du Preez, Solvent Extr. Ion Exch., 20, 359 (2002).

12.- A. Cieszynska and M. Wisniewski, Sep. Purif. Technol., 80, 385 (2011).

13.- M. B. Mooiman, Hydrometallurgy, 16, 245 (1986).

14.- P. A. Riveros, Hydrometallurgy, 24, 135 (1990).

15.- J. Z. Jiang, Y. F. He, H. C. Gao and J. G. Wu, Solvent Extr. Ion Exch., 23 (2005) 113-129.

16.- G. A. Kordosky, J. M. Sierakoski, M. J. Virnig and P. L. Mattison,
Hydrometallurgy, 30, 291 (1992).

17.- M. B. Mooiman and J. D. Miller, Hydrometallurgy, 27, 29 (1991).

18.- X. J. Yang, X. L. Li, K. Huang, Q. Y. Wei, Z. J. Huang, J. Chen and Q. Y. Xie, Miner. Eng., 22, 1068 (2009).

19.- X. J. Yang, K. Huang, Q. Y. Wei, Z. J. Huang, J. Chen and J. G. Wu, Solvent Extr. Ion Exch., 26, 556 (2008).

20.- X. J. Yang, K. Huang, Z. J. Huang, Q. Y. Wei and J. Chen, Solvent Extr. Ion Exch., 25, 299 (2007)

21.- Y. Liu, J. F. Li, J. X Chen, Z.J. Huang and M. H. Liu, Asian J. Chem., 27, 385 (2015).

22.- J. Chen and K. Huang, Hydrometallurgy, 82, 164 (2006).

23.- L. H. Zou, J. Chen and Y. Huang, Hydrometallurgy, 72,31 (2004).

24.- B. Cǒté and G. P. Demopoulos, Solvent Extr. Ion Exch., 12, 393 (1994). 